International

Medical Publisher

http://imedicalpublisher.com

\title{
Nursing Team Training to Use a Flowchart to Care for Patients with Chest Pain
}

\begin{abstract}
Bruna Carolina Lima1', Regimar Carla Machado², Ana Lúcia Gargione Galvão de Sant’Anna², Rosângela Claudia Novembre², Victoria Dorneles Nery², Paulo Willians Lopes², Sueli Fátima Sampaio², Camila Bomfim von Jakitsch ${ }^{2}$
\end{abstract}

\section{Abstract}

Background: Chest pain, of multicausal etiology, associated with a cardiac cause or not, is one of the most frequently presented symptoms by patients in Emergency Care Units. Despite its high prevalence in health services, there is still a deficiency in care standardization, which raises difficulties in acute coronary syndrome diagnosis and delay in treatment. The objective wasto assess the efficiency of professional training of nursing teams in Emergency Care Units on the use of a flowchart to care for patients with chest pain.

Methods and Findings: This educational intervention study was conducted with 25 nursing team professionals. It has been developed in four steps: Step 1 referred to prior application of the validated research instrument. Step 2 comprised training to use the flowchart with an expository lesson on care of patients with chest pain and guidance regarding the flowchart to be implemented. Step 3 reapplied the validated instrument after class. Step 4 reapplied the instrument after 2 months of training for flowchart implementation. When comparing the results of the instrument applied to nursing team professionals, post-training and follow-up performance surpassed that of pre-training. It was observed that professionals with less than five years of experience showed better performance. This study had as limitation the small sample of health professionals participating in the offered training.

Conclusion: Training was satisfactory and significant, and professionals demonstrated content assimilation, obtaining higher scores than at the beginning of the research.
1 Specialization in Nursing in Cardiology and Critical Care. Federal Universityof São Carlos. São Carlos, SP, Brazil.

2 Laboratory of Research in Technology and Innovation in Health - LAPETIS. Federal University of São Paulo. São Paulo, SP, Brazil.

\section{Contact information:}

\section{Regimar Carla Machado.}

Address: Paulista School of Nursing. Federal University of São Paulo. Napoleão de Barros Street, 754. Vila Clementino, São Paulo, Brazil.

Tel: 551155764430 (1682).

Đ regimarcarla@yahoo.com.br

Keywords

Professional Training; Chest Pain; Efficiency; Emergencies; Nursing Team; Workflow. 


\section{Introduction}

Chest pain, of multicausal etiology, is one of the most commonly presented symptoms in Emergency CareUnits, whether associated with a cardiological causeor not. Concerning chest pain assessment, clinical history/physical assessment, electrocardiogram (ECG), and myocardial necrosis markers are fundamental in the investigation of acute coronary syndromes (ACS) [1, 2].

Pain assessment should be detailedto identify heart disease, since it presents different nuances. It is often described as a strong sensation of thoracic oppression, located in the precordial or thoracic region, with irradiation to the neck, jaw, shoulder, and left arm. However, it may manifest as epigastralgia and respiratory distress $[2,3]$.

Patients may also report nausea, vomiting, diaphoresis and lipothymia, worsening pain to physical exertion and emotional stress, as well as improvement in nitrate or rest use. Pain can be continuous and last more than 20 minutes, giving it greater severity; or intermittent, which ceases spontaneously, lasting hours or days $[2,3]$.

During initial care, analysis of symptoms, rapid performance of ECG, and adequate interpretation provide an immediate and effective diagnosis, directing patients to best treatment [3].

It is noteworthy that typical symptoms are present only in a portion of patients. Elderly, women and diabetic individuals may present atypical symptoms, such as epigastralgia and dyspnea, hindering diagnostic accuracy [3].

In diabetic individuals, due to complications arising from neuropathy, subjective symptoms such as mental confusion, dyspnea, nausea, fatigue, syncope, and sweating may prevail, thus demonstrating the importance of team training to recognize pain of ischemic origin, especially nurses who act in risk classification and emergency sectors [4].

Nurses may face difficulties when assessing pain because it is extremely subjective and diverse. The relevant data regarding intensity, duration, periodi- city, location, moment of onset, and factors that improve/worsen chest pain should be explored to obtain adequate characterization and classification [3].

Health services still have deficiencies in care protocols for individuals with chest pain, despite their high prevalence, contributing to the lack of ACS diagnosis and, consequently, delay of appropriate treatment [5].

Updated and qualified protocols provide a safe and evidence-based practice to health institutions, in addition to ensuring knowledge, autonomy, and support to nurses who work directly in the management of patients with chest pain. However, in some emergency services, the use of protocols to unify care has not yet been instituted [5].

The guarantee of adequate and qualified care that includes excellent professional performance, of multicausal etiology, associated with a cardiac causeor not, especially in situations that require a quick and correct decision, permeates continuing education that contributes substantially to implementing and maintaining institutional routines and protocols [6].

Professional training ensures articulation between the needs of users and the quality of care provided by health professionals, resulting from the use of acquired knowledge anddeveloped skills, to fully and effectively assist patients. It also positively impacts the assertive action and motivation of professionals in the short, medium, and long term [7].

In view of the above, it is necessary to assess the efficiency of professional training of nursing teams fromEmergency Care Units on the use of a flowchart to care for patients with chest pain. In view of the severity of possible clinical outcomes, fast, uniform and targeted care is necessary, so that patients can be quickly referred to adequate care in a timely manner for their recovery. 


\section{Method}

This is an educational intervention study originated by the guiding question: Is the training of nursing professionals for the use of a flowchart to care for patients with chest pain effective?

Development took place in 2017, in a city in the countryside of the State of São Paulo, which has an organized network of emergency care, composed of five 24-hour Emergency Care Units, three hospitals with 24-hour care and forty Basic Health Units.

The study site was a 24-hour Emergency Care Unit, standard III, the largest among the models adopted by the Brazilian Ministry of Health, with the capacity to care for 700 patients a day on average, in the ParaíbaValley (Vale do Paraiba) is located in the eastern part of the State of São Paulo, along the Presidente Dutra Highway (BR-101), between Rio de Janeiro and São Paulo).

Sample consisted of nursing team professionals, thus nurses, technicians and nursing assistants, who worked in the unit during the day. Nursing team members were included in case they had been working for at least six months in the unit. Participants who were on vacation, away from the ECU, or refused to participate in the study were excluded.

Simple random sampling was used, relying on the flexibility of the unit to make participants available during their working hours and non-compliance to training outside working hours.

The study was carried out in four steps. Step 1 referred to prior application of the validated instrument. Step 2 comprised training to use the flowchart, with an expository lesson on care of patients with chest pain and guidance regarding the flowchart to be implemented. Step 3reapplied the validated instrument. Step 4 sought after further follow-up, with the application of the instrument after 2 months of training for flowchart implementation.

The instrument for data collection was developed based on scientific literature [1, 8-16]. It was based on the $V$ Guideline of the Brazilian Society of Cardiology on the Treatment of ST-Segment Elevation
Myocardial Infarction (V Diretriz da SociedadeBrasileira de CardiologiasobreTratamento do InfartoAgudo do Miocárdio com Supradesnível do Segmento ST) subsidized by the American Heart Association guidelines [1]. It was previously submitted to appearance validation. The evaluators were a physician and two specialist nurses considered "experts" in theaddressed theme. The selection criteriafor the experts were to be a specialist in cardiology, urgency and emergency or intensive care, and to have a minimum of two years of experience in the hospital area.

The instrument consists of two parts. The first refers to professional characterization, which addresses issues related to age, professional training, sector of professional activity and academic qualification. The second part, concerning the course content, consists of 15 multiple choice questions. Those questions assessed the professional's knowledge regarding the care of patients with chest pain admitted by risk classification after initial care.

The same instrument was applied in all steps, so there was no difference in the degree of difficulty of the questions, enabling the comparison of the participants' performance.

Training to implement a chest pain flowchart occurred in a room destined for continuing education, in the external area of the emergency care unit building, in which groups were formed with a maximum of 6 members, according to unit availability. We used a data show for presentation, which was developed through PowerPoint ${ }^{\circledR}$, with the help of two educational videos on the subject. Explanations were offered about the characteristics of chest pain, the items that should be included in data collection, the care flow of patients with chest pain, the applicable diagnostic tests, ECG interpretation (how to identify ST elevation), and treatments for Acute Myocardial Infarction. Then, the participants' doubts were clarified. The classes were taught in a dialogical way, during the day, lasting thirty minutes, and using the strategies of PowerPoint presen- 
tations, educational video showings, and presentation/application of the research instrument.

Collected data were tabulated electronically in a Microsoft Excel® spreadsheet and analyzed by descriptive statistics, with the elaboration of frequency tables and variable percentages. The Shapiro-Wilk test was applied,since it was a normality test of the samples. Also, after identifying non-normality, the Wilcoxon test was performed, a non-parametric test for comparison of values. For statistical analyses, a significance level of $5 \%$ was established.

The study complies with the formal requirements contained in national and international standards regulating research involving human beings. Research Ethics Committee approved the study, under Opinion 65966317.4.0000.5504, and participants signed the Informed Consent Term.

\section{Results}

Twenty-five nursing team professionals participated in this study, most of them (68.0\%) being nursing technicians (Table 1).

Professional experience was stratified and heterogeneity was identified, as it was found that there were both very experienced professionals and little experienced professionals at the study site. It was found that three of them (12\%) had less than five years of professional experience, six of them (24\%) had up to 10 years of experience, and the majority (64\%) had more than 10-year experience (Table 1).

The age range was from 22 to 54 years old, with the majority (80\%) being between 31 and 50 years old (Table 1). Thus, the average age found in this study was 39.2.

Women prevailed (80\%) in the sample group, and in relation to the length of performance in the unit, the same period was verified for all, since the study site is a new unit opened in July 2016.

Nurses were the professionals who scored the most in all the instruments, with $64 \%$ of the ave-
Table 1. Sociodemographic characterization of the research subjects. São Carlos, SP, Brazil, 2017.

\begin{tabular}{|l|l|l|}
\hline \multicolumn{1}{|c|}{ Variables } & $\mathbf{n}$ & $\%$ \\
\hline Professional category & & \\
\hline Nurse & 05 & 20 \\
\hline Nursing technician & 17 & 68 \\
\hline Nursing assistant & 03 & 12 \\
\hline Length of profession in nursing (years) & & \\
\hline Up to 5 & 03 & 12 \\
\hline 6 to 10 & 06 & 24 \\
\hline 11 to 15 & 05 & 20 \\
\hline 16 to 20 & 05 & 20 \\
\hline 21 to 25 & 02 & 08 \\
\hline$>26$ & 04 & 16 \\
\hline Age group (years) & & \\
\hline$<30$ & 02 & 08 \\
\hline 31 to 40 & 10 & 40 \\
\hline 41 to 50 & 10 & 40 \\
\hline$>50$ & 03 & 12 \\
\hline Sex & & \\
\hline Female & 20 & 80 \\
\hline Male & 05 & 20 \\
\hline
\end{tabular}

rage number of correct answers in the pre-training instrument, $87 \%$ in the post-training instrument, and $84 \%$ of correct answers in the 2-month followup (Table 2).

Nursing technicians obtained similar scores to nursing assistants (Table 2).

The sample presented a satisfactory performance opinion, since most participants obtained more than $50 \%$ of correct answers in all steps of instrument application, with the exception of nursing assistants, who reached $49 \%$ of correct answers in the pre-training instrument (Table 3).

By relating the performances in the instruments pre-training, post-training and follow-up, it is observed that in all professional categories the posttraining and follow-up performances exceeded pretraining ones (Table 3). 
Table 2. Meanvalues of correct answers achieved in assessments according to variables. São Carlos, SP, Brazil, 2017.

\begin{tabular}{|l|l|l|l|l|l|}
\hline \multirow{2}{*}{ Variables } & \multicolumn{4}{|c}{ Mean number of correct answers } \\
\cline { 2 - 5 } & N & Pre & Post & Follow-up \\
\hline Professional category & & & & \\
\hline Nurse & 05 & 64 & 87 & 84 \\
\hline Nursing technician & 17 & 53 & 85 & 77 \\
\hline Nursing assistant & 03 & 49 & 86 & 64 \\
\hline Unit mean number & 25 & 55 & 85 & 77 \\
\hline Length of profession in nursing (years) & & \\
\hline Up to 5 & 03 & 58 & 95 & 83 \\
\hline 6 to 10 & 06 & 56 & 89 & 75 \\
\hline 11 to 15 & 05 & 54 & 87 & 79 \\
\hline 16 to 20 & 05 & 56 & 83 & 71 \\
\hline 21 to 25 & 02 & 47 & 69 & 71 \\
\hline$>26$ & 04 & 55 & 80 & 79 \\
\hline Age group (years) & & & & \\
\hline$<30$ & 02 & 67 & 89 & 75 \\
\hline 31 to 40 & 10 & 53 & 90 & 84 \\
\hline 41 to 50 & 10 & 55 & 81 & 76 \\
\hline 50 & 03 & 58 & 83 & 62 \\
\hline Sex & & & & \\
\hline Male & 05 & 57 & 83 & 70 \\
\hline Female & 20 & 54 & 86 & 78 \\
\hline
\end{tabular}

Different proportions of correct answers were observed in allapplied instruments (Table 3).

When comparing pre-training and post-training performances, the minimum (-0.600) and maximum $(-0.066)$ values of the differences are negative and indicate an increase in the proportions of correctness. When comparing post-training with followup, the average of the positive differences (0.083) indicates a decrease in the proportion of correct answers when follow-up was answered. However, in relation to pre-training and follow-up, the mean value of the differences was negative, indicating that there was an increase in the proportion of correct answers when follow-up (Table 3) was applied.

\section{Discussion}

The present study, carried out through an educational intervention with 25 nursing professionals from an Emergency Care Unit, was developed in four steps: application of a theoretical instrument before and after the training to use a chest pain flowchart, and follow-up instrument application after two months. When comparing the results of the instrument applied to nursing team professionals, post-training and follow-up performances exceeded that of pre-training.

Table 3. Wilcoxon test paired for pre-capacitation, post-capacitation, follow-up samples, and descriptive statistics of differences. São Carlos, SP, Brazil, 2017.

\begin{tabular}{|c|c|c|c|c|c|c|}
\hline Samples & $\begin{array}{c}\text { Statistics } \\
\text { Test }\end{array}$ & P value & Conclusion & $\begin{array}{c}\text { Difference } \\
\text { Minimum }\end{array}$ & $\begin{array}{c}\text { Mean difference } \\
\text { values }\end{array}$ & $\begin{array}{c}\text { Maximum } \\
\text { Difference }\end{array}$ \\
\hline Pre- Post & 0 & $<0.001$ & $\begin{array}{c}\text { Equality of } \\
\text { medians is } \\
\text { rejected. }\end{array}$ & -0.600 & -0.245 & -0.066 \\
\hline Post - Follow up & 212 & 0.025 & $\begin{array}{c}\text { Equality of } \\
\text { medians is } \\
\text { rejected. }\end{array}$ & -0.333 & 0.083 & 0.333 \\
\hline Pre - Follow up & 32 & $<0.001$ & $\begin{array}{c}\text { Equality of } \\
\text { medians is } \\
\text { rejected. }\end{array}$ & -0.533 & -0.168 & 0.133 \\
\hline
\end{tabular}


Concerning professional category, nursing technicians were the most observed participants. In the Brazilian nursing context, there is greater representation among nursing technicians and assistants $[8,9]$. A study on the socioeconomic, epidemiological and occupational characterization of nursing professionals showed that of the 393 participants, 295 (75\%) were nursing technicians. It was also observed that the sample was composed mostly of female professionals, with 316 (80\%) of theparticipants [8].

Feminization is imperative among health professionals, since over $90 \%$ of nursing positions are taken by these workers [8]. This study obtained similar data, as $20 \%$ of the participants were male and $80 \%$ were female. The same also occurred in a theoretical training for nurses on Cardiorespiratory Arrest (CRP), divided into a control and an experimental group, in which females were the prevalent gender on both groups [10].

It was observed that there is important heterogeneity in the age group of the participants, with a higher prevalence of the age group from 30 to 50 years, followed by those over 50 years old and then those under 30 years old, characterizing a mixed team with professionals who go through different steps and experiences, at a mean value of 39.3 years.

The average age of nursing professionals is in the young adult cycle. Thus, the literature identifies small variations to the averages of age, corroborating that nursing teams in health care establishments are composed mainly of young people, as demonstrated in a study where the average age was 40 years [10], and in a study that revealed an average of 30 to 39 years for the participating nursing professionals [8].

Data showed that a small part of the sample has professional experience of up to five years, highlighting those with 11 to 20 years of experience as the majority of the sample. Time passed after graduation as well as career length are impor- tant factors for learning, since they are the guiding thread of learning, that happens through recurring observation of theory and practice [11].

In an analysis of the effects of nursing training, focused on the assessment of patients with stroke, using the application of a pre-test and a post-test, a considerable rate of previous correctness and high post-test correctness were found [12]. Data showed an increase in the performance of trained nurses. That information can also be grasped from this study, especially when higher accuracy was observed in the follow-up than at the beginning of the study.

It is relevant to point out that the follow-up scores remain above pre-training ones, even if performed after a considerable time, therefore it is inferred that the strategy used in the teaching-learning process of training truly provided positive contributions to the development and assimilation of the content, thusindicatingeffective learning by the research participants.

In a similar investigation, researchers sought to perform a training through the application of three identical tests: an immediate test (step I), a test after one week (step II) and a late one after three months (step III). The participants were divided into two groups, control and experimental, in which one of them received training after the first test, while the other did not [10]. During the first test, a slightly low score was reached. In the second test, the scores increased and in a third moment, considered late, the development remained higher than in the first test, just as it is observed in the present study [10].

The development noticed post-training is in line with the literature $[5,7,9,10,12,13]$, demonstrating that learning was achieved in a short time span. In-service training seeks the improvement ofusual activities that guide knowledge, so professionals can develop skills and behaviors that are necessary to improve their results in the institution [6], thus showing the importance of performing this type of interventionfor clinical practice. 
In a multivariate analysis, referring to the professional category, it was observed that nurses obtained a higher number of correct answers in the theoretical instrument pre-training, post-training and in the follow-up, respectively. Since the functions are divided by levels of complexity and professional training, it is expected that nurses will perform better due to their academic background, the complexity of their competencies and theirexclusive character. This result could be observed in this study, when verifying the best performance of nurses in the steps, both in pre and post-test and follow-up, compared to the other professional categories with lower education, even though they were fewer in the sample group.

It is important to include all professional categories of the nursing team to promote early detection of the alterations presented by the patient, and to institute appropriate conducts to restore health and protect life [17]. Furthermore, this study presented as a limitation the small sample of health professionals participating in theoffered training.

In general, there was uniformity in the scores, which can be related to age and consequently the length of professional performance in the area.

It was observed that professionals with work experience of five years at most obtained higher scores in all applied tests, always staying above the mean value of correct answers in pre-training, with an increase in post-training and a small decrease in the follow-up score. On the other hand, a study that addresses the assessment applied to the participants of an admission program for nursing showed a positive correlation between the grades obtained by the participants and the length of experience in the profession, making it possible to observe thatthe longer one's professional practice was, the better was their performance as candidates taking the tests; a result which differs from the findings in the present study [6].

When analyzing the performance by age, the participants aged 31 to 40 years, characterized as young adults, presented a higher number of correct answers, however, the professionals over 50 years old and who consequently assumed that they would have more experience, were the ones who scored the least in the follow-up. Thus, the study demonstrated the need to stimulate this category of participants to acquire new knowledge and willingness to change.

Health institutions seek educational actions for their health professionals in order to favor the quality of health care and improve the performance of the professional team $[18,19]$. Professional training is an essential strategy to qualify human resources in order to increase the knowledge of specific areas and obtain systematized and organized care, positively impacting the problem-solving capacity of professionals and the quality of provided care, as it stimulates the discussion of content, adapts professionals tocare practice based on scientific evidence, besides the fact it adds value to the professional [20].

It is noteworthy that in-service training of health professionals through continuing education is one of the recommended strategies contained in thestrategic action plan to combat chronic non-communicable diseases, in force until 2022 in Brazil [21].

One of the devices used to train health professionals is the dialogical expository class, such as the one used in this study, where the teacher presents content and promotes active participation of students, who can contribute, discuss and request clarification, providing active construction of knowledge and greater interaction [22]. It is a strategy characterized by content display with active participation of listeners, considering previous knowledge, so the teacher is the mediator for students to question, interpret and discuss the object of study [23].

This resource, combined with an environment in which respect and dialogue predominate, enables acquisition of knowledge through mobilization of 
previous experiences. This strategy becomes more effective as the capacity for interaction between the subjects of the teaching-learning process increases, establishing an environment of respect and trust in the search for new knowledge [24].

\section{Conclusion}

Training related to care for patients with chest pain was satisfactory, achieving a significant increase in the mean number of correct answers by health professionals. Corroborating the literature, the test applied after training obtained high rates of correct answers in allassessed variables, demonstrating that short-term training was effective, concise and achieved the objective of preparing them for adequate care for patients with chest pain in the emergency department. Studies with greater scope should be conducted in order to prove the effectiveness of health professional training for patient care.

\section{Competing and conflicting interests}

None of the authors received any kind of financial support that could be considered a potential conflict of interest in relation to the manuscript or its submission.

\section{References}

1. Piegas LS, Timerman A, Feitosa GS, Nicolau JC, Mattos LAP, Andrade MD, et al. V Diretriz da Socieda de Brasileira de Cardiologia sobre Tratamento do Infarto Agudo do Miocárdio com Supradesnível do Segmento ST. Arq Bras Cardiol. 2015; 105(2):1-105. doi:10.5935/abc.20150107

2. Ouchia JD, Teixeira C, Ribeiro CAG, Oliveira CC. Arrival time of Infarcted Patient in the Intensive Care Unit: importance of fast care services. Cienc Biol Agrar Saúde. 2017; 21(2):92-7. doi: 10.17921/1415-6938

3. Reggi S, Estefanini E. Diagnóstico das síndromes coronarianas agudas e modelo sistematizado de atendimento em unidades de dor torácica. Rev Soc Cardiol Estado de São Paulo. 2016; 26(2):78-85. Available from: http://www.socesp.org.br/upload/ revista/2016/L60-REVISTA-SOCESP-V26-N2-12-07-16.pdf
4. CHP, Moreira RSL, Guizzilini S, Santos VB. Peripheral neuropaty and clinical signs of acute coronary syndrome in patients with diabetes mellitus. Cogitare Enferm. 2017; (22)1:e48491. doi:10.5380/ce.v22i1.48491.

5. Farias MM, Moreira DM. Impacto de protocolo de dor torácica sobre a adesão às diretrizes societárias: um ensaio clínico. Rev Bras Cardiol [Internet]. 2012 [citado 2018 mar 13]; 25(5):36876. Available from: www.onlineijcs.com/exportar-pdf/185/ v25n05a02.pdf

6. Sapatini TF, Gasparino RC, Polli L, Oliveira AS. Evaluation of an admission program for the nursing team. Esc Anna Nery. 2016; 20(3):e20160065. doi:10.5935/1414-8145.20160065.

7. Mira VL, Peduzzi M, Melleiro MM, Tronchin DMR, Prado MFF, Santos PT et al. Analysis of the learning evaluation process of nursing staff factions. Rev Esc Enferm USP. 2011;45:1574-81. doi:10.1590/S0080-62342011000700006

8. Santos SVM, Macedo FRM, Resck ZMR, Sanches RS, Nogueira DA, Terra FS. Socioeconomic, Epidemiological and Labor Characteristics of Hospital Nurses. RevEnferm Centro-Oeste Mineiro. 2017; 7:e1391. doi:10.19175/recom.v7i0.1391

9. Ternopolski CA, Baratieri T, Lenstck MH. Eventos adversos pósvacinação: educação permanente para a equipe de enfermagem. Rev Espaço Saúde. 2015; 16(4):109-19. doi:10.22421/15177130.2015v16n4p109

10. Bellan MC, Araújo IIM, Araújo S. Capacitação teórica do enfermeiro para o atendimento da parada cardiorrespiratória. Rev Bras Enferm. 2010; 63(6):1019-27. doi:10.1590/S003471672010000600023

11. Miyahira CK, Martins MRI, Mendonça RCHU, Cesarino CB. Avaliação da dor torácica, sono e qualidade de vida de pacientes com doença renal crônica. Arq Ciênc Saúde. 2016; 23(4):61-6. doi:10.17696/2318-3691.23.4.2016.486

12. Santos JVS, Melo EA, Silveira Junior JL, Vasconcelos NN, Lima MC, Damázio LCM. The effects of nursing training on the evaluation of patients with cerebrovascular accident. Rev Enferm UFPE on line;11(5):1763-8. doi: 10.5205/reuol.11077-98857-1SM.1105201702

13. Mira VL, Follador NN, Ferrari CRS, Oliveira LFMN, Silva JAM, SantosPT. Avaliação da eficácia de um treinamento de profissionais de enfermagem: estudo correlacional. Online Braz J Nurs [Internet]. 2012 [citado 2018 mar 13]; 11(3). Available from: $\quad$ https://www.objnursing.uff.br/index.php/nursing/rt/ printerFriendly/3652/html

14. Hospital Sírio Libanês. Protocolo de síndrome coronariana aguda (SCA) [Internet]. 2013 [citado 2017 mar 20]. Available from: https://www.hospitalsiriolibanes.org.br/institucional/ gestao-da-qualidade/Documents/protocolo-sca.pdf.

15. Gomes ET, Queiroga AV, Araújo NR, Bezerra SMMS. Chest pain during admission in a reference cardiac emergency unit. Rev Rene. 2014; 15(3):508-15. doi:15253/2175-6783.2014000300016 
16. Dias PAP, Oliveira WA. Avaliação do protocolo de dor torácica no hospital do coração do Brasil. RevCient Sena Aires [Internet]. 2016 [citado 2018 mar 13]; 5(2):44-57. Available from: http:// revistafacesa.senaaires.com.br/index.php/revisa/article/ view/265

17. Ferreira ND, de Almeida Rocha G, da Silva IC, Loureiro LH. Capacitação em saúde: estratégia assistencial aos portadores de tuberculose. Pesquisa em Foco. 2019; 24(2):41-60. doi:10.18817/ pef.v24i2.2114

18. Mello AL, Backes DS, Terra MG, Rangel RF, Nietsche EA, Salbego C. (Re) pensando a educação permanente com base em novas metodologias de intervenção em saúde. Rev. Cubana Enferm. 2017. [acesso em 2017 dez 17]; 33(3). Available from: http:// www.revenfermeria.sld.cu/index.php/enf/article/view/1104.

19. Sade PMCS, Peres AM, Brusamarelo T, Mercês NNA, Wolff LDG, Lowen IMV. Continuous nursing education requirements in a teaching hospital. Cogitare Enferm. 2019; 24:e57130. doi: 10.5380/ce.v24i0.57130

20. Marcondes FL, Tavares CMM, Santos GS, Silva TN, Silveira PG. Capacitação profissional de enfermagem na atenção primária à saúde: revisão integrativa. Revista Pró- Univer SUS. 2015 Jul./ Dez.; 06 (3): 09-15.

21. Ministério da Saúde (BR). Secretaria de Vigilância em Saúde. Departamento de Análise de Situação de Saúde. Plano de ações estratégicas para o enfrentamento das doenças crônicas não transmissíveis (DCNT) no Brasil 2011-2022. Brasília: Ministério da Saúde; 2011. 148 p. [citado em 2018 set. 12]. Available from: http://bvsms.saude.gov.br/bvs/publicacoes/plano acoes enfrent dent 2011.pdf
22. Sá EF, Quadros AL, Mortimer EF, Silva PS, Talim SL. As aulas de graduação em uma universidade pública federal: planejamento, estratégias didáticas e engajamento dos estudantes. RBE, 2017. 22 (70): 625-50. doi: 10.1590/s1413-24782017227032

23. Sousa AS; Oliveira FCS; Vieira J. Análise de jogos e modelos didáticos no ensino de biologia, associados à aula expositiva dialogada na área de Citologia. 2019. 132 p. Trabalho de Conclusão de Mestrado (Mestrado em Ensino de Biologia) Universidade Estadual do Piauí. Teresina. Available from: http:// sistemas2.uespi.br:8080/ handle/tede/231

24. Lopes TO. Aula expositiva dialogada e aula simulada: comparação entre estratégias de ensino na graduação de enfermagem, 2012. 125 p. Dissertação (Mestrado), Escola de Enfermagem da Universidade de São Paulo, São Paulo, 2012. Available from: http://teses.usp.br/teses/disponiveis/7/7140/tde16052012-104658/pt-br.php
Publish in International Archives of Medicine

International Archives of Medicine is an open access journal publishing articles encompassing all aspects of medical science and clinical practice. IAM is considered a megajournal with independent sections on all areas of medicine. IAM is a really international journal with authors and board members from all around the world. 